\title{
Pengaruh Variasi Dimensi Superkonduktor Berbentuk Persegi Panjang Terhadap Medan Kritis Pada Pada $\kappa=1,5$
}

\author{
Alqaan Maqbullah Ilmi ${ }^{1}$, Cari $^{1}$, Fuad Anwar ${ }^{1}$ \\ ${ }^{1}$ Program Studi S2 Ilmu Fisika, Pascasarjana Universitas Sebelas Maret, \\ Jl. Ir. Sutami no 36 Kentingan Surakarta \\ Email : fanwar@staff.uns.ac.id
}

\begin{abstract}
The Time Dependent Ginzburg-Landau (TDGL) equation can be used to study the characteristics of a superconductor in the evolution of time until it reaches an equilibrium state. This study uses the YU method to calculate the critical field value numerically which has been tested stable and consistent. Previous research has been carried out regarding the critical field ratio of rectangular and rectangular superconductors with the same area at $\kappa=1.5$. This research examines the variation of the dimensions of the type II superconductor with a rectangular shape, then it is found that the critical field of the Hc surface forms a pattern that can be used to study the characteristics of the type II superconductor.
\end{abstract}

Keywords: type II-superconductor, critical field, TDGL equation, psi-U

\begin{abstract}
Abstrak: Persamaan Ginzburg-Landau Gayut Waktu (Time Dependent Ginzburg-Landau/TDGL) dapat digunakan untuk mempelajari karakteristik superkonduktor dalam evolusi waktu sampai mencapai keadaan setimbang. Penelitian ini menggunakan metode $\Psi U$ untuk menghitung nilai medan kritis secara numerik yang telah teruji stabil dan konsisten. Telah dilakukan penelitian sebelumnya mengenai perbandingan medan kritis superkonduktor berbentuk persegi dan persegi panjang dengan luas sama pada $\kappa=1,5$. Dalam penelitian ini dikaji variasi dimensi superkonduktor tipe II dengan bentuk persegi panjang, kemudian didapatkan bahwa medan kritis permukaan $\mathrm{Hc}_{3}$ membentuk pola yang dapat digunakan untuk mempelajari karakteristik superkonduktor tipe II.
\end{abstract}

Kata kunci: superkonduktor tipe II, medan kritis, persamaan ginzburg-landau gayut waktu, psi-U

\section{PENDAHULUAN}

Qiang (2005), Rosyida, dkk (2004) dan Anwar, dkk (2017) telah melakukan kajian numerik untuk menyelesaikan persamaan TDGL secara komputasi. Dalam perhitungannya, menggunakan metode $\psi U$ dengan memperoleh hasil yang tetap konvergen (Winiecki dan Adams, 2002). Selain parameter $\kappa$ dan ukuran, pengaruh medan kritis juga didpatkan dari Efek Proksimitas (Anwar, 2015) dan Efek Bifurkasi (Ma dan Wang, 2005). Anwary, dkk (2018) melakukan perhitungan untuk variasi parameter $\kappa$ bilangan bulat mendapati adanya pengaruh pada perubahan medan kritis. Poskarina, dkk (2018) melakukan perhitungan menggunakan variasi ukuran dengan bentuk persegi panjang mendapati bahwa semakin besar ukuran berpengaruh pada medan kritis. Anwar, dkk (2019) dan Ilmi, dkk (2019) melakukan penelitian pada superkonduktor berbentuk persegi dengan $\kappa=1,5$. Penelitian ini mempelajari pengaruh variasi dimensi terhadap medan kritis pada superkonduktor tipe II dengan bentuk persegi panjang dengan $\kappa=1,5$.

\section{METODE PENELITIAN}

Pencarian nilai medan kritis dari persamaan TDGL tidak bisa dilakukan secara analitis karena persamaan bersifat kompleks dan terkopel sehingga dilakukan perhitungan secara komputasi. Penelitian ini menggunakan bahan superkonduktor berbentuk persegi dengan 
ukuran sisi $N x$ dan $N y$ kemudian dikenai medan magnet luar $H_{\text {ext }}$ yang seragam searah sumbu $z$ positif dan juga gayut waktu sebagaimana pada gambar 1 .

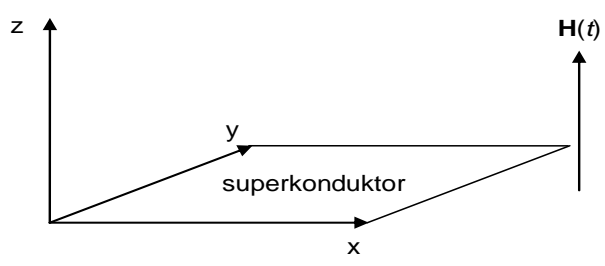

Gambar 1. Skema superkonduktor yang diteliti

Penggunaan metode $\psi U$ berarti bahan superkonduktor dianggap tersusun atas sekumpulan sel dengan ukuran $\Delta x \times \Delta y$ (Winiecki dan Adams, 2002). Sel tersebut mengandung tiga besaran fundamental yakni $\psi_{i j}, U^{x}$ dan $U^{y}$ sebagaimana tampak pada gambar 2.

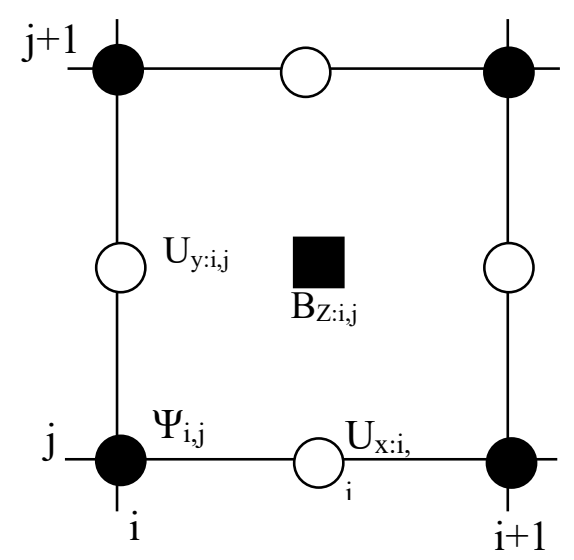

Gambar 2. Skema metode $\psi U$

Kajian terhadap karakteristik superkonduktor dilakukan dengan menghitung secara numerik menggunakan persamaan TDGL (Ilmi, dkk, 2019). Persamaan Ginzburg Landau Gayut Waktu dapat dituliskan sebagai berikut :

$$
\begin{aligned}
& \frac{\partial \psi(\mathbf{r}, t)}{\partial t}=(\nabla-i \mathbf{A}(\mathbf{r}, t))^{2} \psi(\mathbf{r}, t)+\psi(\mathbf{r}, t)-|\psi(\mathbf{r}, t)|^{2} \psi(\mathbf{r}, t) \\
& \sigma \frac{\partial \mathbf{A}(\mathbf{r}, t)}{\partial t}=\frac{1}{2 i}\left(\bar{\psi}(\mathbf{r}, t) \nabla \psi(\mathbf{r}, t)-\psi(\mathbf{r}, t) \nabla \bar{\psi}(\mathbf{r}, t)-2 i|\psi(\mathbf{r}, t)|^{2} \mathbf{A}(\mathbf{r}, t)\right)-\kappa^{2}(T) \nabla \times\left(\nabla \times \mathbf{A}(\mathbf{r}, t)-\mathbf{H}_{e x t}(\mathbf{r}, t)\right)
\end{aligned}
$$

Dengan syarat batas parameter benahannya adalah

$$
\hat{\mathbf{n}} \cdot\left[\nabla-\frac{i e_{s}}{\hbar} \mathbf{A}\right] \psi=0
$$

Dan syarat batas medan magnetnya adalah

$$
\mathbf{H}_{e x t}=\nabla \times \mathbf{A}
$$


Nilai psikuadrat yang didapat persamaan TDGL dan syarat batas secara teknis dapat diamati dari nilai perbandingan keliling dan luas superkonduktor. Nilai perbandingan keliling per luas yang mendekati nol menunjukkan bahwa persamaan syarat batas tidak banyak berpengaruh sehingga untuk ukuran ini dapat dikategorikan sebagai bongkahan besar.

\section{HASIL DAN PEMBAHASAN}

Sifat superkonduktor dapat diamati dari nilai $H c_{1}$ dan $H c_{3} . H c_{1}$ adalah medan kritis pertama dimana telah terjadi penembusan medan magnet laur ke dalam bingkahan superkonduktor sehingga terjadi kondisi campuran (mixstate). Suzuki (2007) menjelaskan bahwa $H c_{1}$ dapat dicari ketika terjadi titik balik pada psikuadrat, yaitu ketika psi kuadrat yang pertama kali menunjukkan kenaikan. $H_{c}$ adalah kondisi dimana Superkonduktor telah kehilangan sifat konduktivitasnya secara total. $\mathrm{Hc}_{3}$ dicari dengan cara mencari medan magnet eksternal dimana psi kuadrat pertama kali bernilai nol. Cyrot dan Pavuna (1992) menunjukkan bahwa kondisi ini terjadi saat bahan telah kehilangan sifat superkonduktornya secara total.

Grafik psikuadrat pada gambar 3-7 menunjukkan kondisi tercapainya $H c_{1}$ yakni saat terjadi penurunan pertama pada grafik dan $H c_{3}$ yakni saat menyentuh angka nol pertama kali. Gambar 3 merupakan bentuk paling sederhana dari grafik dimana sangat tampak jelas $H c_{1}$ dan $H c_{3}$.

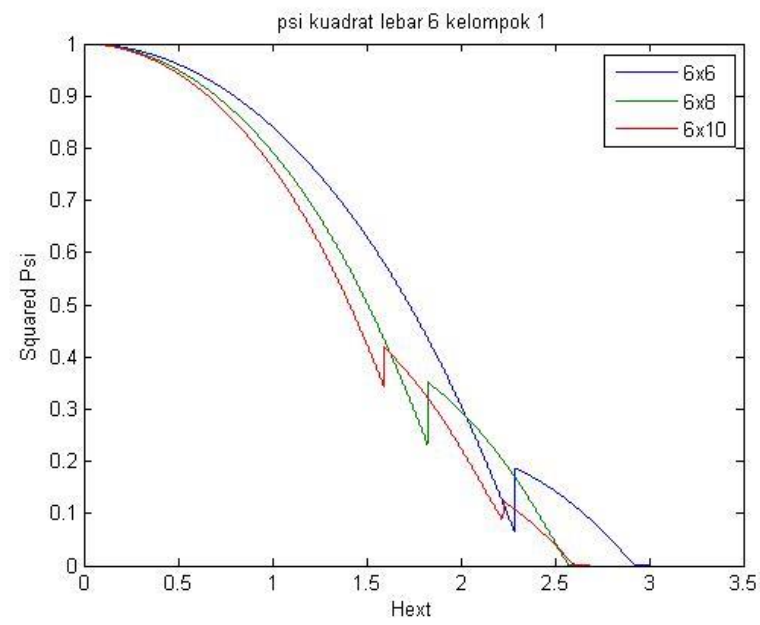

Gambar 3. Psikuadrat untuk ukuran $24 \times 18,24 \times 20,24 \times 22,48 \times 18,48 \times 20$, dan 48x22

Gambar 4-8 merupakan grafik psikuadrat untuk ukuran sedang dan besar dimana nampak adanya kesamaan nilai $H c_{1}$ dan $H c_{3}$. Namun dalam proses perhitungannya memiliki selisih nilai yang cukup berbeda sebagaimana tampak pada grafik. Nampak pada gambar 4-8 membandingkan kedua kelompok varian $N y$ yang sama namun pada nilai $N x$ yang berbeda. 

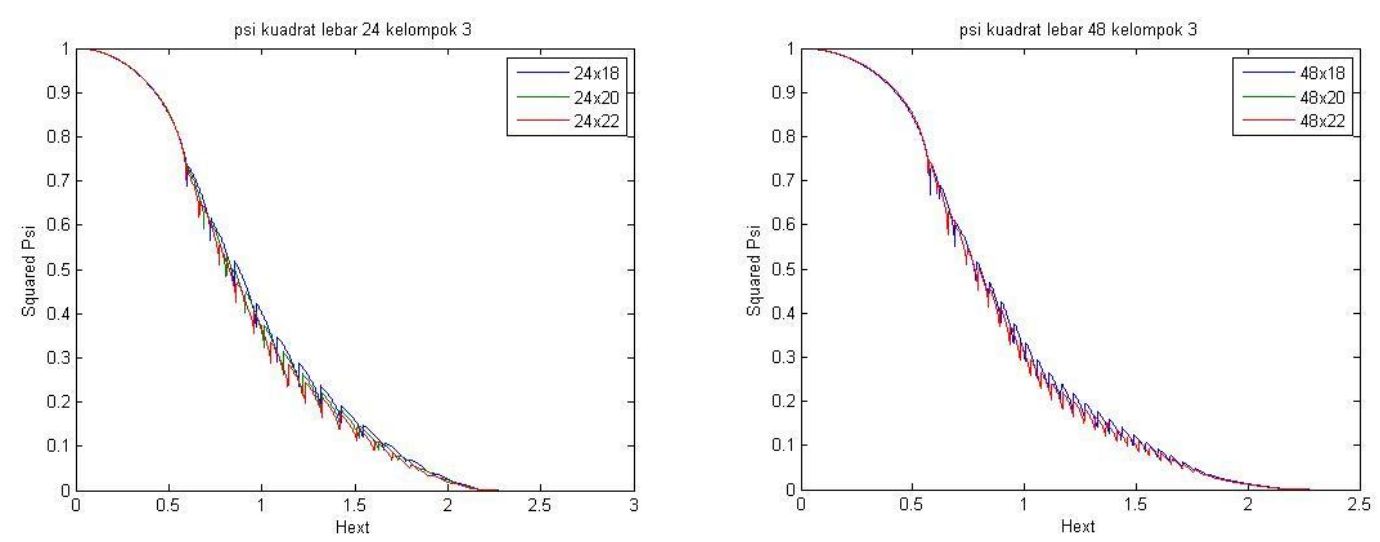

Gambar 4. Psikuadrat untuk ukuran 24x18, 24x20, 24x22, 48x18, 48x20, dan 48x22
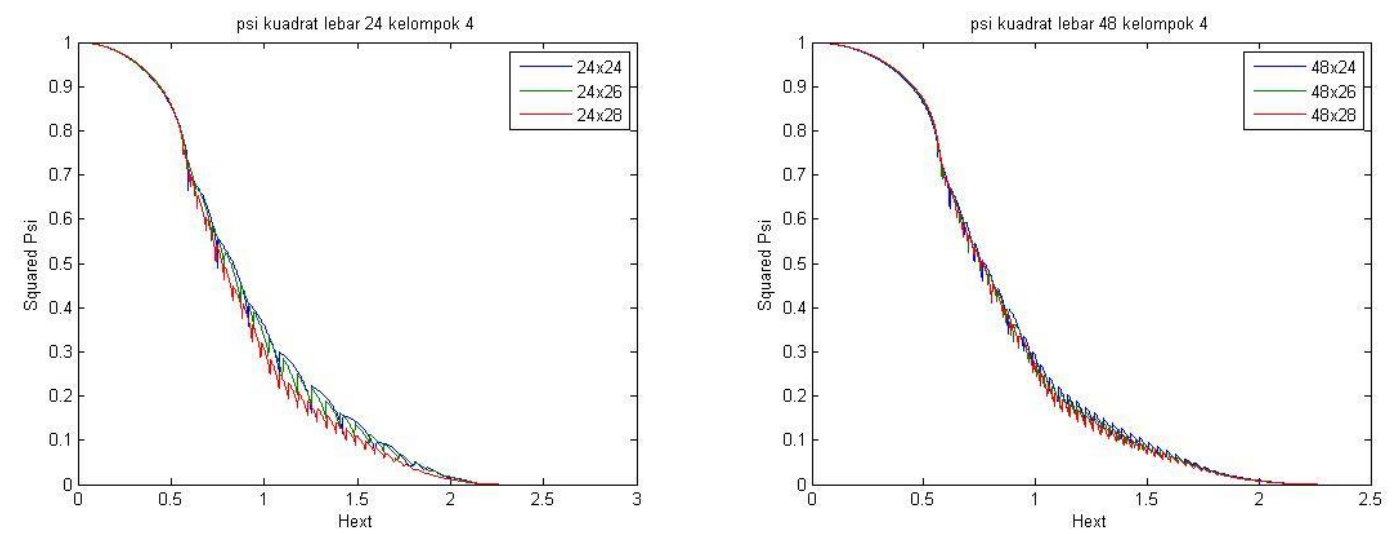

Gambar 5. Psikuadrat untuk ukuran $24 \times 24,24 \times 26,24 \times 28,48 \times 24,48 \times 26$, dan 48x28
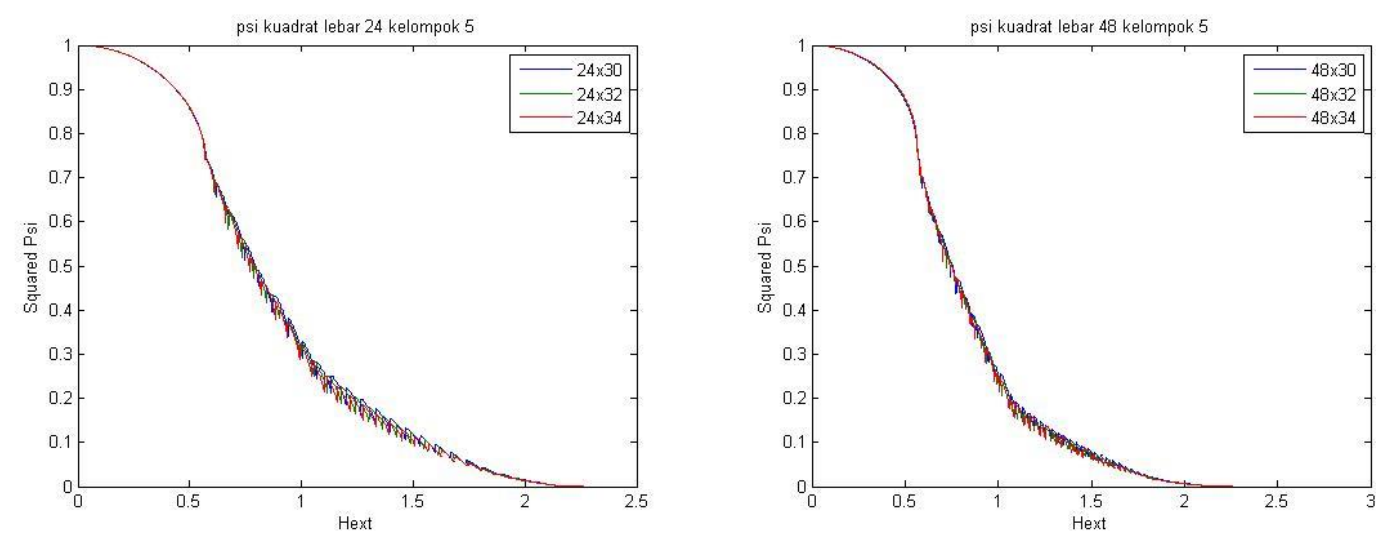

Gambar 6. Psikuadrat untuk ukuran 24x30, 24x32, 24x36, 48x30, 48x32, dan 48x34 

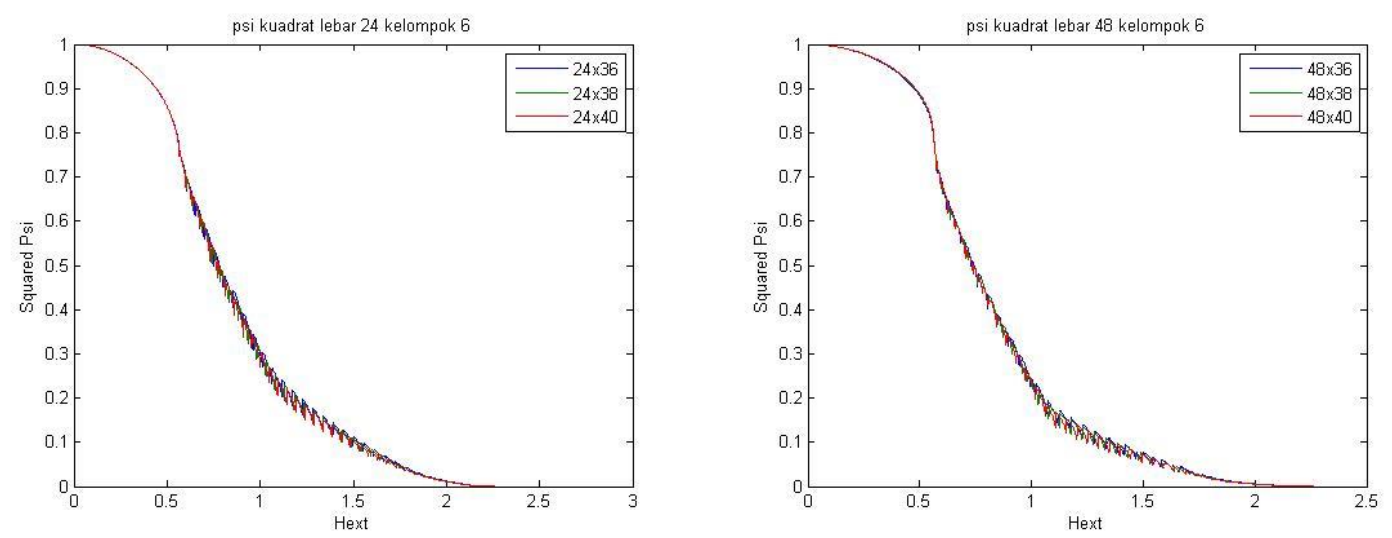

Gambar 7. Psikuadrat untuk ukuran 24x36, 24x38, 24x40, 48x36, 48x38, dan 48x40
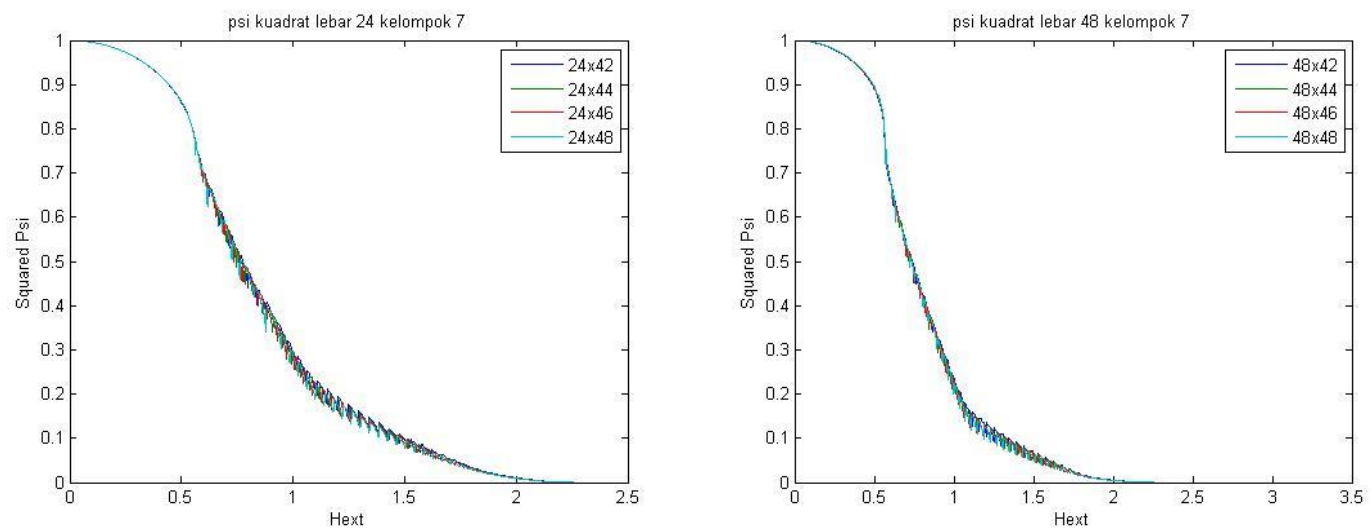

Gambar 8. Psikuadrat untuk ukuran 24x42, 24x44, 24x46, 24x48, 48x42, 48x44, 48x46 dan $48 \times 48$

Gambar 9 dan 10 merupakan rangkuman dari data yang didapatkan dari seluruh grafik psikuadrat. Terlihat bahwa nilai medan kritis mulai stabil pada $N y=14$. Sehingga dapat dikatakan bahwa untuk ukuran di bawah 14 adalah kecil. Nampak pula pada gambar 9 dan 10 bahwa untuk Nx yang bernilai 24 dan 48 bernilai sama karena nilainya telah lebih dari 14 sehingga menunjukkan kestabilan.

\section{Hc1}

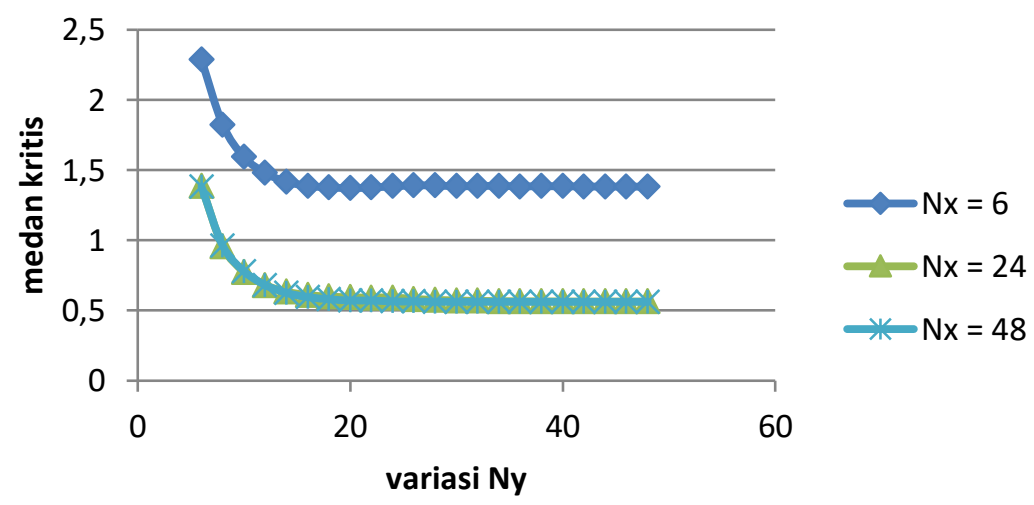

Gambar 9. Rangkuman $H c_{1}$ 


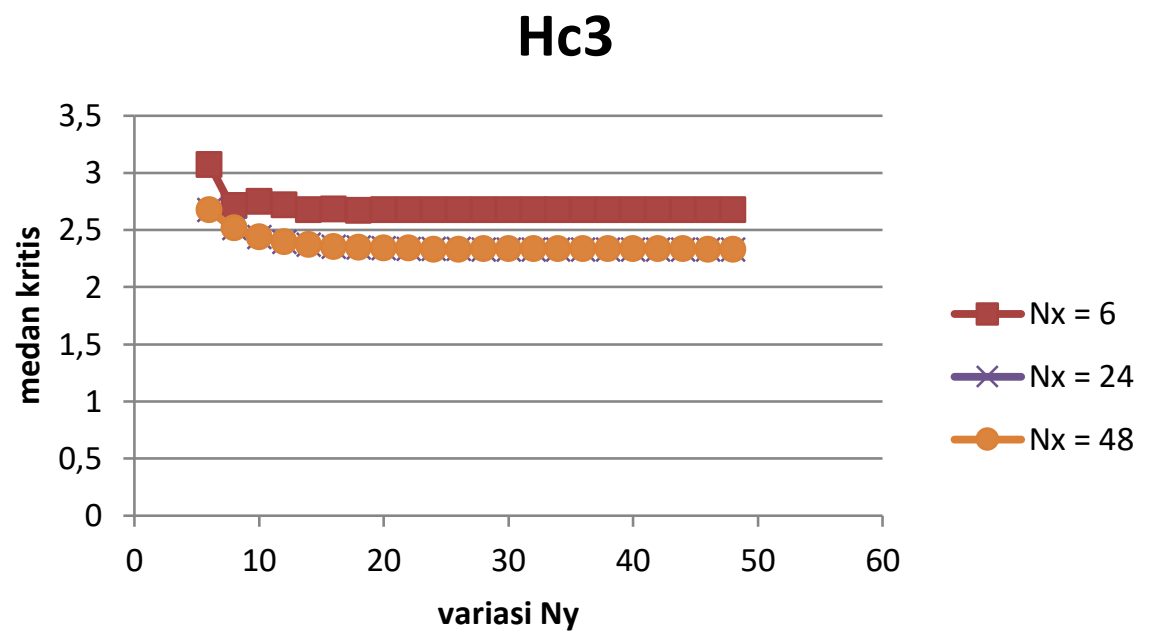

Gambar 10. Rangkuman $H c_{3}$

Gambar 11-20 semakin memperjelas pengelompokan superkonduktor berdasarkan ukurannya yakni menjadi ukuran sedang dan besar dengan ukuran 30 sebagai batasnya. Dimulai dari ukuran 30, nilai medan kritis yang sama itupun dicapai pada nilai step yang sama sehingga dapat dikatakan bahwa nilai medan kritis tersebut dicapai pada waktu perhitungan numerik yang sama. $H c_{1}$ dicapai pada step 58000 sedangkan $H c_{3}$ pada step 234000.
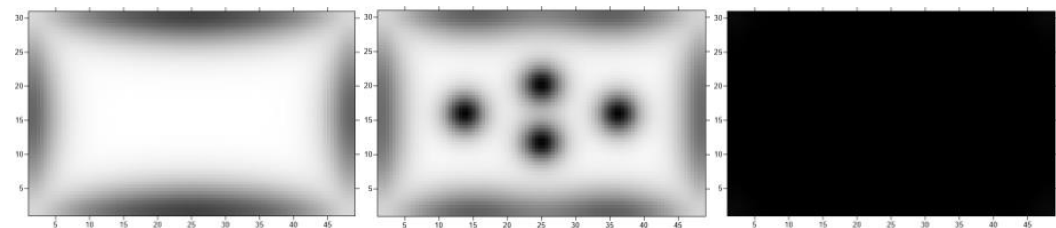

Gambar 11. Tampilan vortex untuk ukuran $48 \times 30$ dari kiri ke kanan pada step : 56000 (perembesan tepi), $58000\left(H c_{1}\right), 234000\left(H c_{3}\right)$
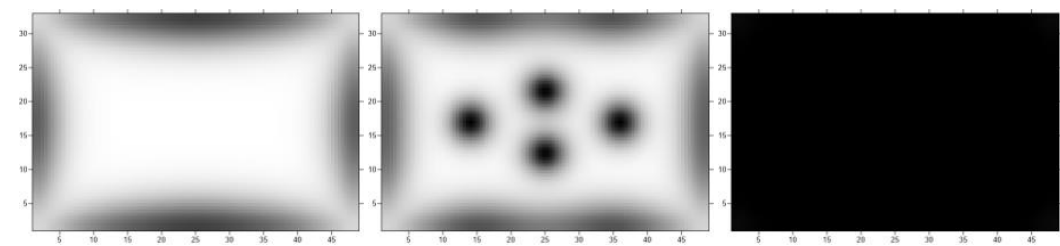

Gambar 12. Tampilan vortex untuk ukuran $48 \times 32$ dari kiri ke kanan pada step : 56000 (perembesan tepi), $58000\left(H c_{1}\right), 234000\left(H c_{3}\right)$
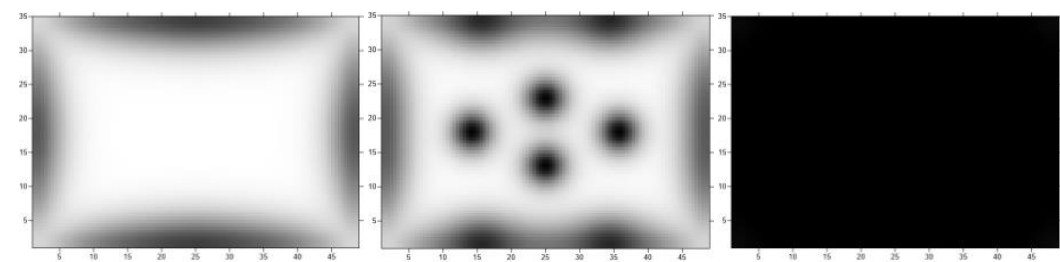

Gambar 13. Tampilan vortex untuk ukuran $48 \times 34$ dari kiri ke kanan pada step : 56000 (perembesan tepi), $58000\left(H c_{1}\right), 234000\left(H c_{3}\right)$ 

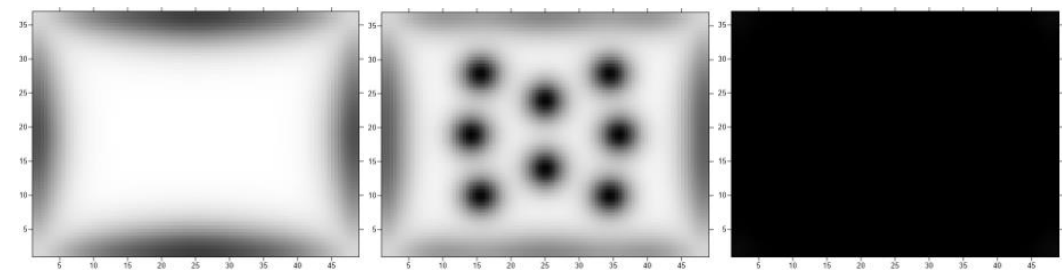

Gambar 14. Tampilan vortex untuk ukuran $48 \times 36$ dari kiri ke kanan pada step : 56000 (perembesan tepi), $58000\left(H c_{1}\right), 234000\left(H c_{3}\right)$
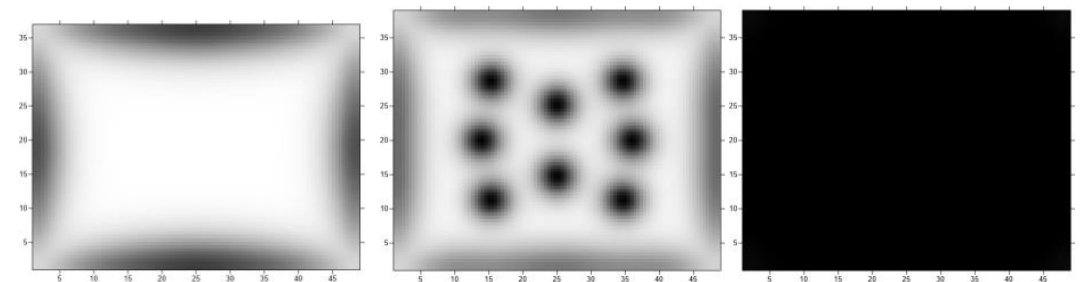

Gambar 15. Tampilan vortex untuk ukuran $48 \times 38$ dari kiri ke kanan pada step : 56000 (perembesan tepi), $58000\left(H c_{1}\right), 234000\left(H c_{3}\right)$
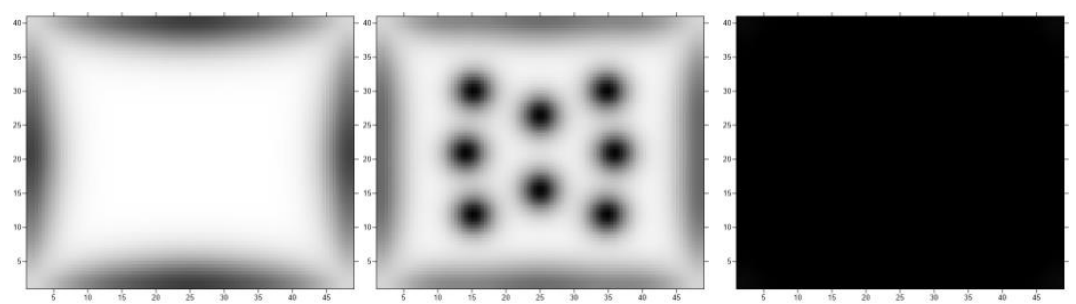

Gambar 16. Tampilan vortex untuk ukuran $48 \times 40$ dari kiri ke kanan pada step : 56000 (perembesan tepi), $58000\left(H c_{1}\right), 234000\left(H c_{3}\right)$
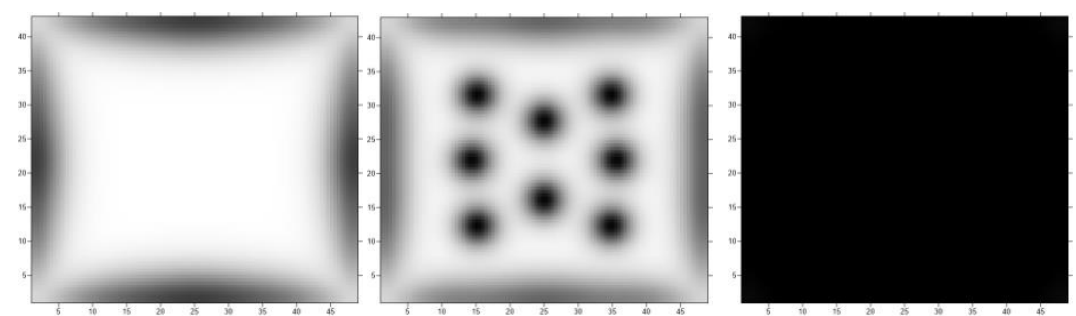

Gambar 17. Tampilan vortex untuk ukuran $48 \times 42$ dari kiri ke kanan pada step : 56000 (perembesan tepi), $58000\left(H c_{1}\right), 234000\left(H c_{3}\right)$
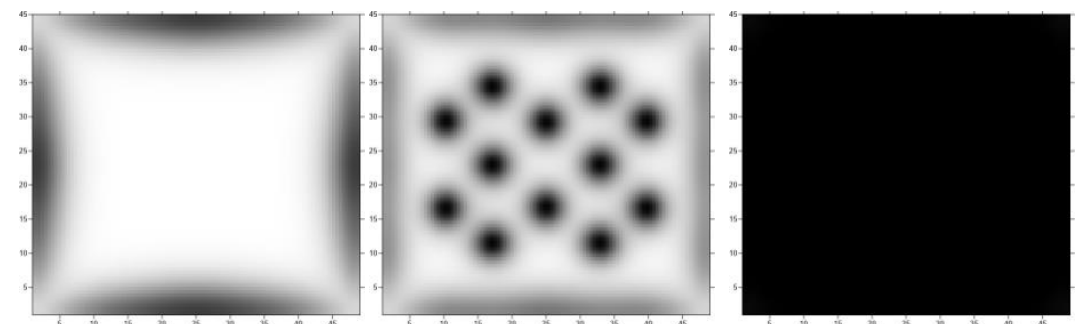

Gambar 18. Tampilan vortex untuk ukuran $48 x 44$ dari kiri ke kanan pada step : 56000 (perembesan tepi), $58000\left(H c_{1}\right), 234000\left(H c_{3}\right)$ 


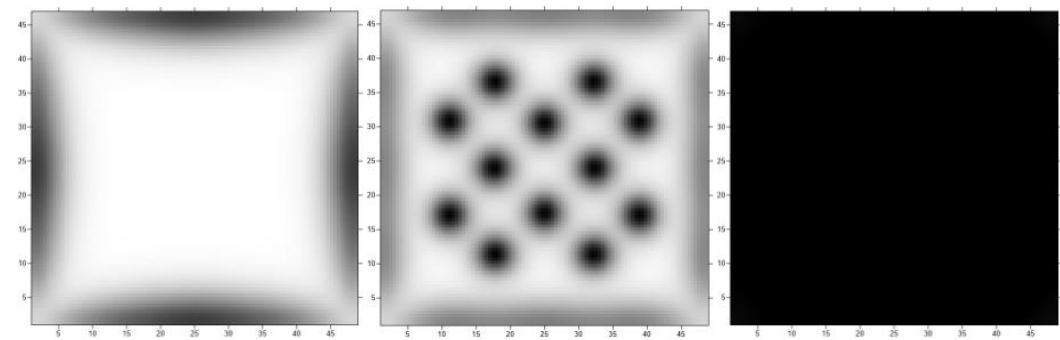

Gambar 19. Tampilan vortex untuk ukuran $48 \times 46$ dari kiri ke kanan pada step : 56000 (perembesan tepi), $58000\left(H c_{1}\right), 234000\left(H c_{3}\right)$
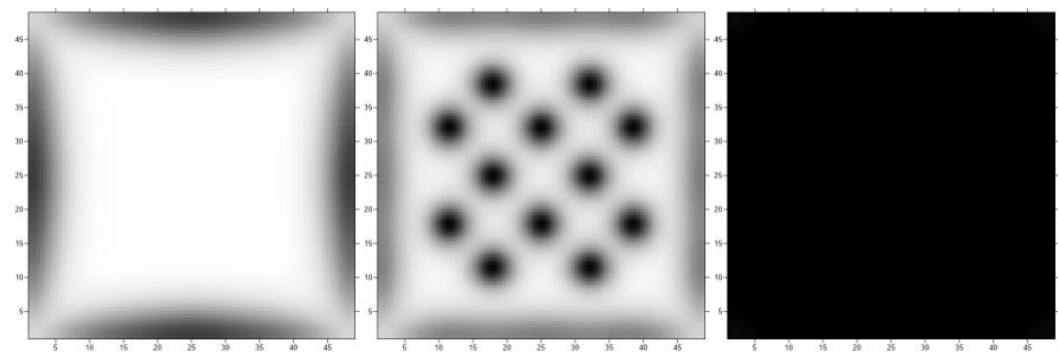

Gambar 20. Tampilan vortex untuk ukuran $48 \times 48$ dari kiri ke kanan pada step : 56000 (perembesan tepi), $58000\left(H c_{1}\right), 234000\left(H c_{3}\right)$

Tampilan vortex juga menunjukkan adanya kesamaan pola pada beberapa ukuran yakni pola pertama pada gambar 11-13, pola kedua pada gambar 14-17 dan pola ketiga pada gambar 1820. Kopnin (2006) dan Tinkham (1996) mengatakan bahwa pengaruh variasi ukuran pada medan kritis ini terkait pada dalamnya penetrasi medan eksternal terhadap bahan. $H c_{1}$ merupakan medan kritis rendah dimana medan external mulai menembus bahan superkonduktor dalam bentuk vortex. Hal ini menunjukkan bahwa medan magnet eksternal telah berhasil menembus sebagian dari bahan namun sebagian lainnya masih bersifat superkonduktor, atau disebut juga sebagai mixed state. Sedangkan $\mathrm{Hc}_{3}$ adalah medan external yang mampu menghilangkan secara total sifat superkonduktor.

\section{KESIMPULAN}

Telah berhasil dihitung medan kritis pada superkonduktor tipe II untuk $\kappa=1,5$ untuk mengkaji pengaruh variasi dimensi superkonduktor tipe II dengan bentuk persegi panjang. Dalam penelitian ini ditemukan pengelompokkan superkonduktor berdasarkan ukurannya dengan mengacu pada kesamaan sifat yang ditunjukkan pada data nilai $H c_{1}, H c_{3}$ dan step masing-masingnya. Superkonduktor ukuran kecil yakni untuk ukuran 12 atau kurang darinya dimana tampak bahwa masih terdapat penurunan nilai medan kritis dikarenakan nilainya masih dipengaruhi oleh syarat batas. Superkonduktor ukuran sedang yakni ukuran 14-28 dimana tampak ada kesamaan nilai medan kritisnya meski ukurannya berbeda. Superkonduktor ukuran besar yakni ukuran 30 atau lebih besar darinya dimana tampak bahwa tidak hanya medan kritisnya yang sama namun nilai medan kritis tersebut juga tercapai pada step yang sama untuk semua ukuran.

\section{DAFTAR PUSTAKA}

A.M. Ilmi, Cari dan F. Anwar. Dimension effect on critical field of superconductor when Ginzburg-Landau is 1.5. AIP Conference Proceedings 2202, 020006 (2019).

D, Qiang. Numerical approximations of the Ginzburg-Landau models for superconductivity. Journal of Mathematical Physics, 46, 2005, pp. 1-22. 
F. Anwar, P. Nurwantoro, dan A. Hermanto. Kajian Medan Kritis pada Penyelesaian Komputasi Persamaan Ginzburg-Landau Gayut Waktu. Prosiding Pertemuan Ilmiah XXVIII HFI Jateng \& DIY, Yogyakarta, April 2014, pp. 145-148.

F. Anwar. Kajian Model : Pengaruh Efek Proksimitas dan Efek tak Isotrop pada Sifat Magnet Superkonduktor Mesoskopik Tipe II. Doctoral dissertation. UGM, Yogyakarta, 2015

F. Anwar, C. Cari, dan A.M. Ilmi. Comparison of the superconducting rectangular critical fields with the same area at $\kappa=1.5$, Journal of Physics : Theories and Applications, vol 3, no 2, 2019, pp. 62-68

M. Cyrot dan M. Pavuna. Introduction to Superconductivity and High Tc Material, World Scientific Publication co. Ptc. Ltd., Singapore, 1992.

M. Suzuki dan I.S. Suzuki. Lecture Note on Solid State Physics Ginzburg-Landau Theory for Superconductivity. State University of Newyork, Newyork, 2007.

N. Poskarina, F. Anwar, dan A. D. Sutomo, Kajian Pengaruh Parameter Ginzburg-Landau terhadap Medan Kritis Superkonduktor Tipe II Berbentuk Persegi Panjang, Prosiding Seminar Nasional Quantum, vol. 25, 2018, pp. 699-704.

N.B. Kopnin. Theory of Superconductivity. Helsinki University of Technology, 2006.

R Rosyida, F. Anwar, and Darmanto. Numerical simulation of dimension effect on critical field of rectangular superconductor. International Conference on Science and Applied Science, 2017, pp. 1-5.

R. Anwary, F. Anwar dan H. Purwanto. Kajian pengaruh variasi luasan terhadap sifat-sifat superkonduktor Tipe II berbentuk persegi panjang pada keadaan efek proksimitas. Prosiding Seminar Nasional Quantum, vol. 25, April 2018, pp. 724-731.

T. Ma and S. Wang, Bifurcation and stability of superconductivity, Journal of Mathematical Physics, vol. 46, 2005, pp. 1-31.

T. Winiecki and C. S. Adams. A Fast Semi-Implicit Finite-Difference Method for the TDGL Equations. Journal of Computational Physics, 179, 2002, pp. 127-139.

Tinkham, M., 1996, Introduction to Superconductivity, McGraw-Hill Inc., Singapore. 